\title{
Seismic Performance of Reinforced Concrete Frames with Precast- Prestressed Flooring System
}

\author{
Authors: \\ Brian H.H. Peng, University of Canterbury, New Zealand, hhp10@student.canterbury.ac.nz \\ Richard Fenwick, University of Canterbury, NZ, richard.fenwick@canterbury.ac.nz \\ Rajesh Dhakal, University of Canterbury, NZ, rajesh.dhakal@canterbury.ac.nz \\ Athol Carr, University of Canterbury, NZ, athol.carr@canterbury.ac.nz
}

\begin{abstract}
In a current research project the influence that floor slabs containing precast prestressed units have on the seismic performance of plastic hinges in beams of moment resisting frames is being examined. A three dimensional, approximately half scale, one storey, two bay moment resisting frame together with adjacent floor slab has been constructed and tested. The experimental results show that the building code, ACI 318-05, underestimates the flexural strength of beams by a considerable margin. An analytical model has been developed which predicts the flexural, shear and elongation response of plastic hinges in beams subjected to inelastic rotation history and varying axial load levels. This model can be used to predict the interaction between beams in moment resisting frames and floor slabs containing precast prestressed units. Analysis using this model shows good agreement with the experimental results.
\end{abstract}

\section{INTRODUCTION}

Recent experimental studies in New Zealand have shown that the presence of prestressed floor units can increase the strength of the beams much more than that specified in the major structural codes [Lau, 2007; Matthews, 2004]. This level of strength enhancement has raised concern as it may shift the designed ductile beam sway mechanism to an undesirable column sway mechanism in an event of a major earthquake. As the level of strength enhancement varies with different structural arrangements, test results by themselves cannot readily be used to develop satisfactory design rules due to wide range of structural arrangments and prestressed flooring systems used in practice. Repetitive experimental studies on this topic would be complex, time and resource consuming, therefore numerical simulation provides a more feasible alternative.

To analytically simulate strength enhancement of beams with cast-in-situ slabs containing prestressed floor units, the element representing the plastic hinge region must be able to predict elongation response of plastic hinges. An analytical plastic hinge element has been developed in this research to captured beam elongation. An approximately half scale, 3D sub-assembly test unit of a two-bay reinforced concrete frame with associated floor slab containing precastprestressed floor units was built and tested to investigate the mechanisms associated with floorframe interaction and to provide data and experimental validation of the analytical model.

This paper summarizes the results obtained from the 3D experiment and analysis. The main focus is on elongation, flexural strength of beams and frame-floor interaction. 


\section{EXPERIMENTAL RESEARCH}

\section{Sub-assembly Construction and Test Arrangement}

The test unit consisted of a one storey, two bay moment-resisting frame with transverse beams connected into each column and with a floor slab containing prestressed units as shown in Figure 1. The floor contained $100 \mathrm{~mm}$ deep precast-prestressed ribs supported on transverse beams with a layer of cast-in-situ concrete topping as illustrated in Figure 2. Grade 300, 10mm deformed bars were placed in the concrete topping at $210 \mathrm{~mm}$ centers in both directions. These were lapped to $10 \mathrm{~mm}$ starter bars along the perimeter beams. The floor was connected to a $175 \mathrm{~mm}$ thick end slab to represent the stiff continuation of floor diaphragm in the rest of the building.

Columns in the moment frames were supported on two way linear bearings to allow movement in the horizontal plane. These columns were designed to remain elastic through out the test to ensure the maximum strength of plastic hinges could develop in the beams. The exterior transverse beams were supported on steel columns with one way linear bearing allowing floor movement parallel to frame. The interior transverse beam was supported on steel column with ball bearings that allow floor movement in the horizontal plane.
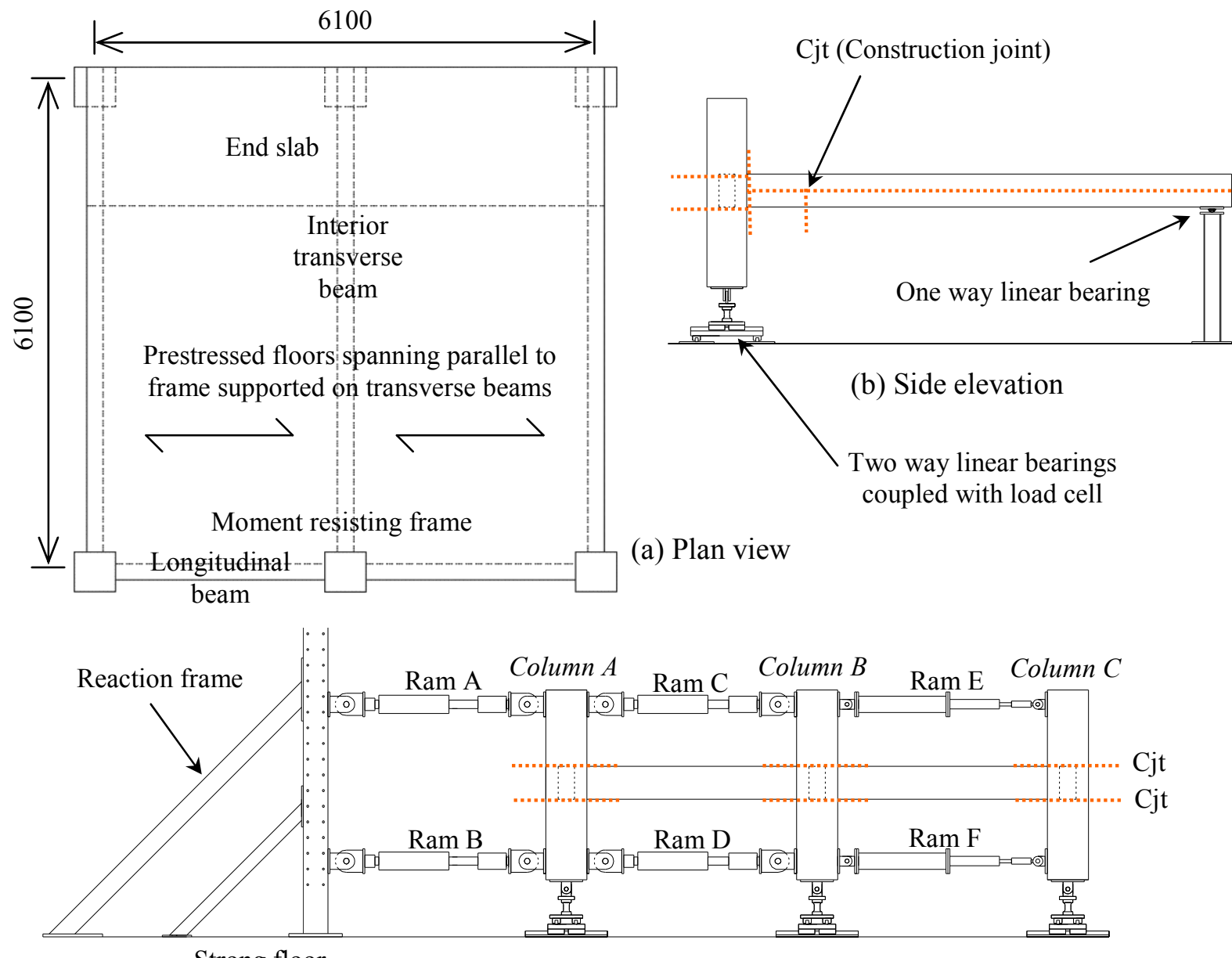

Strong floor

(c) Front elevation

FIGURE 1 - SUB-ASSEMBLY SETUP 
The sub-assembly was built in four stages. First, the three bottom portions of the columns with the full length of longitudinal reinforcement projecting out to the top, full depth longitudinal beam including beam-column joints with floor and transverse beam starter bars sticking out to the side and three half height transverse beams were precast. The beam-column joints contained ducts to allow the column reinforcing bars to pass through. These precast members were then erected and the beam-column joints grouted. Next, the top of columns and the lap splices between the transverse beams and beam-column joints were cast. Lastly, the prestressed ribs were placed between the transverse beams and the floor topping and rest of the transverse beams were cast.

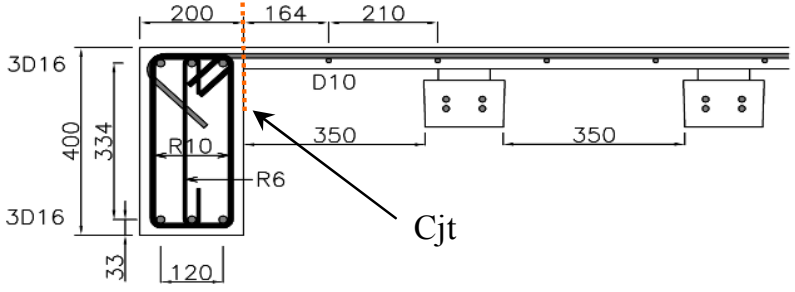

(a) Longitudinal beam and slab

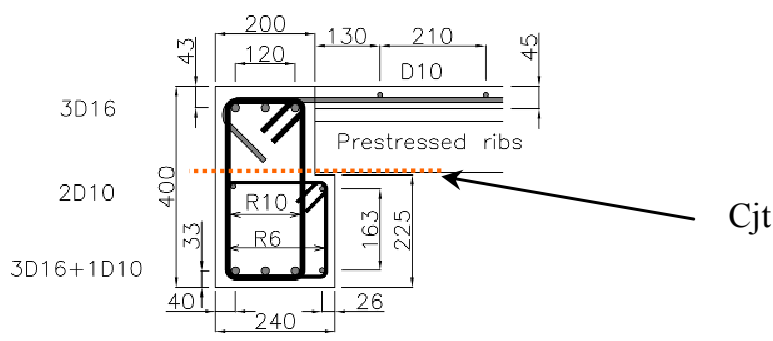

(c) Exterior transverse beam

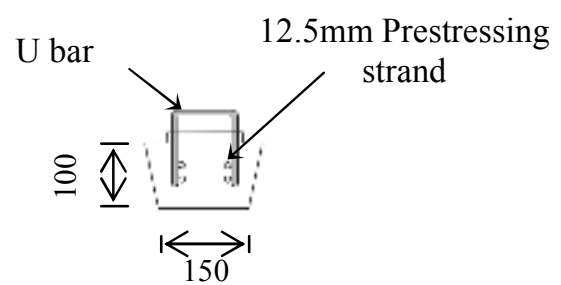

(b) Stahlton prestressed ribs

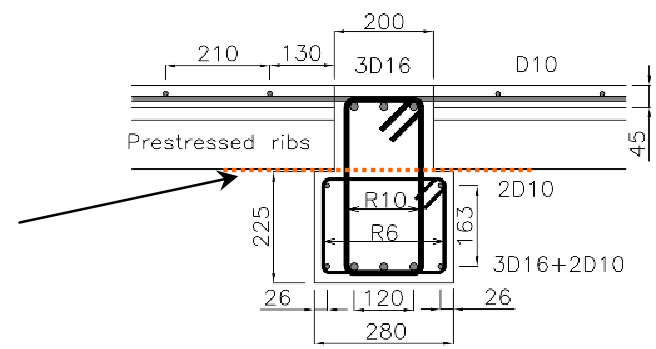

(d) Interior transverse beam

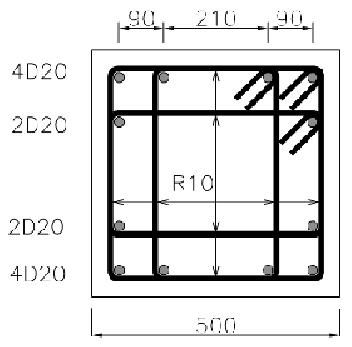

(e) Column

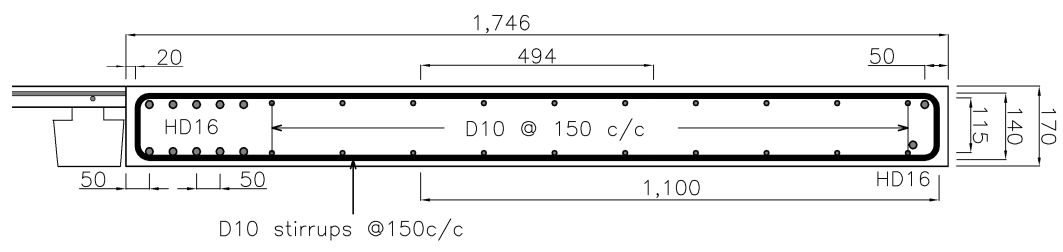

(f) End slab

FIGURE 2 - CROSS SECTION DETAILS OF KEY STRUCTURAL MEMBERS

\section{Loading Protocol and Instrumentation}

The loading was displacement controlled; quasi-static cyclic loading was applied to the top and bottom of each column through six hydraulic rams as illustrated in Figure 1(c). The loading history started with one cycle at $\pm 0.15 \%$ drift, followed by two cycles at $\pm 0.25 \%, \pm 0.35 \%$ and $\pm 0.5 \%$ drifts. These were made to check the loading regime, control system, instrumentation and to obtain the overall elastic response of the sub-assembly. Following these elastic cycles, two cycles at $\pm 0.75 \%$, and $\pm 1 \%$ drifts were applied; in subsequent cycles the peak displacements were increased in increments of $0.5 \%$ drift until the peak lateral force in a cycle was less than 
$65 \%$ of the maximum force sustained. In between each peak drift magnitude, a small cycle equal to $30 \%$ of the large cycle amplitude was applied.

Within each incremental step, the displacements at the top and bottom of each column were corrected iteratively to ensure that the three columns remained parallel to each other and that the force acting at the top of each column was equal and opposite to the force acting at the bottom of each column. This ensured that beam elongation was not externally restrained and no axial load was induced in the beams by the hydraulic rams. For example, if the combined forces in the column in a displacement increment induced compression force to a beam; the pair of actuators was extended by the same amount until the combined forces were equal to zero.

The sub-assemblage was extensively instrumented with load cells, linear and rotary potentiometers, inclinometers, DEMEC points and sonic displacement transducers to gather as much information as possible on the force-displacement response and the deformations sustained in the test unit. A total of 253 channels were used to record the experimental data. In addition, 1100 DEMEC readings were taken on the floor at the selected peak displacements.

\section{EXPERIMENTAL OBSERVATIONS}

The averaged concrete compression strengths at the start of test for the three different casts were 31.2MPa, 42.4MPa and 33MPa respectively. The averaged properties of the reinforcement in the beams and floor slab are summarized in TABLE 1 where $f_{y}, f_{u}$ are the yield and ultimate stress respectively; $\varepsilon_{y}, \varepsilon_{s h}, \varepsilon_{u}$, are the yield, strain hardening and ultimate strain respectively; $R$ and $D$ stands for Grade 300 round and deformed bars and $H D$ stands for Grade 500 deformed bar. The number following the letters represents the diameter of the reinforcing bars in millimeter.

\begin{tabular}{|c|c|c|c|c|c|}
\hline Steel & $\boldsymbol{f}_{\boldsymbol{y}}(\mathbf{M P a})$ & $\boldsymbol{f}_{\boldsymbol{u}}(\mathbf{M P a})$ & $\boldsymbol{\varepsilon}_{\boldsymbol{v}}$ & $\boldsymbol{\varepsilon}_{\boldsymbol{s} \boldsymbol{h}}$ & $\boldsymbol{\varepsilon}_{\boldsymbol{u}}$ \\
\hline$R 6$ & 444.7 & 557.1 & 0.0022 & - & 0.0916 \\
\hline$R 10$ & 395.2 & 490.5 & 0.0020 & 0.0174 & 0.1355 \\
\hline$D 10$ & 372.5 & 477.1 & 0.0019 & 0.0189 & 0.1209 \\
\hline$D 16$ & 325.4 & 454.9 & 0.0016 & 0.0253 & 0.2084 \\
\hline
\end{tabular}

\section{TABLE 1 - PROPERTIES OF REINFORCEMENT IN BEAMS AND CONCRETE TOPPING}

Minor flexural cracking appeared in the longitudinal beams and floor slab at $0.25 \%$ drift. Flexural cracks in the beams became inclined diagonally at $0.35 \%$ drift; minor cracking in the columns and prestressed floor-transverse beams interface also became apparent. At $0.5 \%$ drift, diagonal cracks developed in the floor and cracks were observed in the center beam-column joint. First signs of yielding occurred at $0.75 \%$ drift; at the same drift cycle, diagonal cracks were observed in the central beam-column joint. At 1\% drift, diagonal torsional cracks developed in the transverse beams. Differential vertical and horizontal movement between floor and beams became apparent at $1.5 \%$ drift. At $2 \%$ drift, minor concrete spalling was observed in the exterior plastic hinges. At 3\% drift, minor concrete spalling was observed underneath the floor slab; exterior columns were found to twist outwards. Some of the bottom reinforcing bars in the exterior plastic hinges buckled at 3\% drift and fractured at 3.5\% drift. At $4.5 \%$ drift, all the bottom reinforcing bars in exterior plastic hinges fractured and the force decreased to $65 \%$ of the maximum force sustained in the test.

The photos in Figure 3 show the damage to the sub-assembly at the end of test. It can be seen that region around the exterior plastic hinges suffered more damage than the interior plastic hinges. This is because elongation of interior plastic hinges was restrained by the floor slab. This 
is also reflected by the permanent cracks widths that developed at the interface between prestressed ribs and transverse beams, shown in Figure 3(c) and (d). The overall cracks pattern on the floor slab at the end of test is plotted in Figure 4. It can be seen that many cracks formed parallel, perpendicular and diagonally to the frame. The diagonal cracks were inclined towards the interior column. The cracks parallel to frame were initiated close to the interior transverse beam and extended across the slab. This crack pattern and the way they developed implies that the floor slab was restraining elongation of interior plastic hinges with the slabs on each side of the central transverse beam acting as a deep beams.

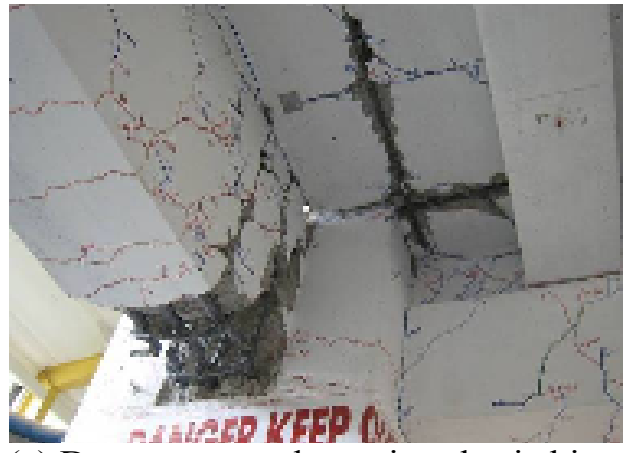

(a) Damage around exterior plastic hinge

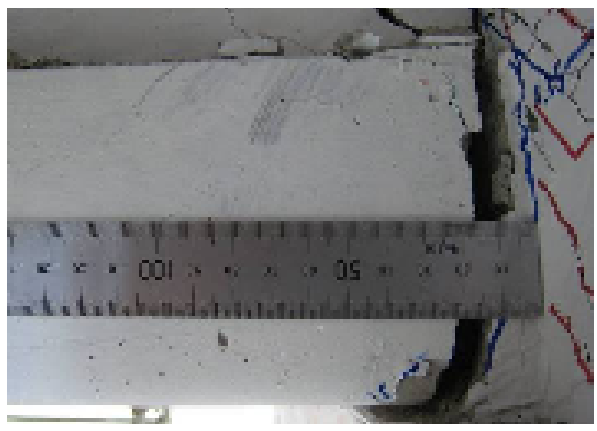

(c) Prestressed rib next to exterior plastic hinge

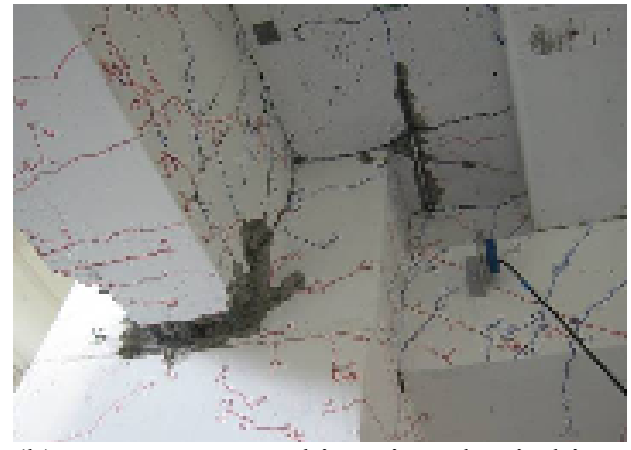

(b) Damage around interior plastic hinge

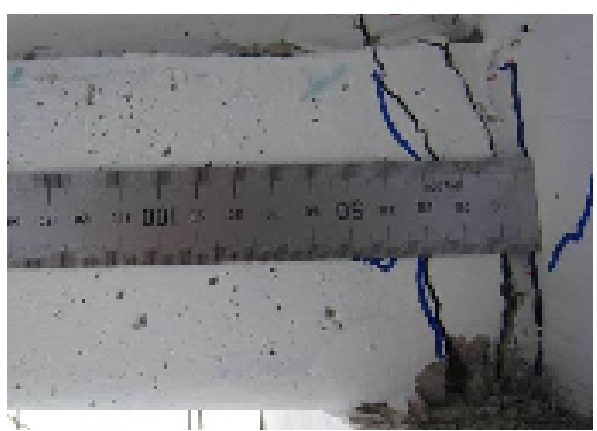

(d) Prestressed rib next to interior plastic hinge

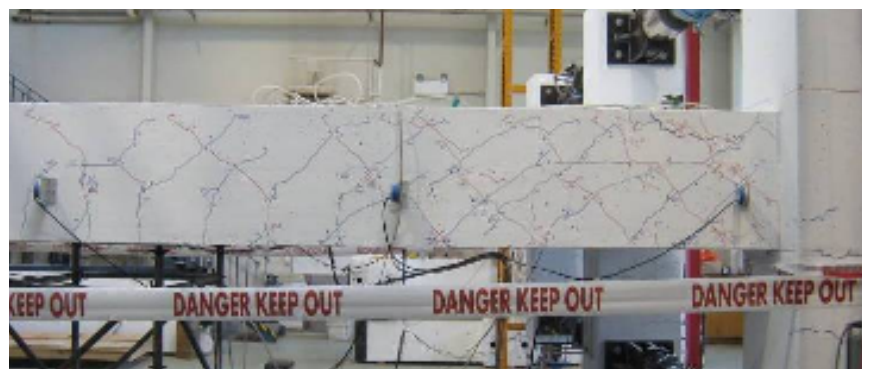

(e) Torsional cracks in transverse beam

\section{FIGURE 3 - DAMAGE IN THE MEMBERS OBSERVED AT THE END OF TEST}

The total force-displacement response of the sub-assembly is shown in Figure 5. Yielding of the longitudinal reinforcement in the exterior plastic hinges occurred close to $1 \%$ drift. Maximum lateral forces of $333 \mathrm{kN}$ and $320 \mathrm{kN}$ in the positive and negative drifts respectively were reached at 3\% drift. The provision in ACI 318-05 [American concrete institute, 2005] for calculating the flexural strength of T-beams with a flange on one side is based on empirical beam-column results at $2 \%$ drift [Jirsa, 1991]. This criterion gives an effective flange width of 
$210 \mathrm{~mm}$ for this test unit. To design the flexural strength of columns, an over-strength value of 1.2 is specified. The corresponding total lateral force of the sub-assembly is shown in Figure 5. It can be seen that the code specified column strength is significantly lower than the experimentally measured value. This level of underestimation in beam strength might result in the development of a column sway mechanism.

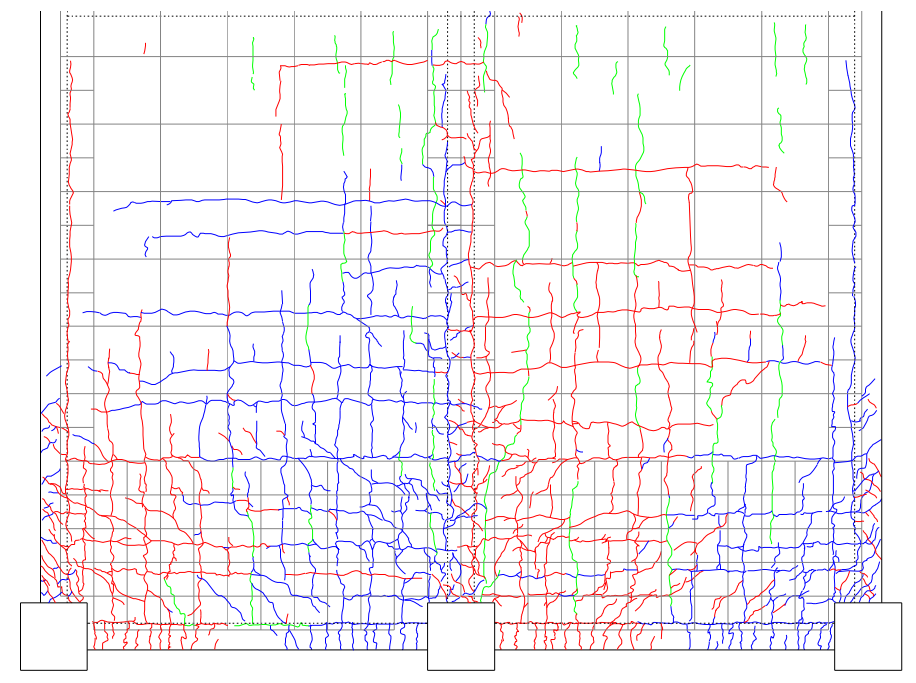

FIGURE 4 - OVERALL CRACKS PATTERN ON THE FLOOR SLAB

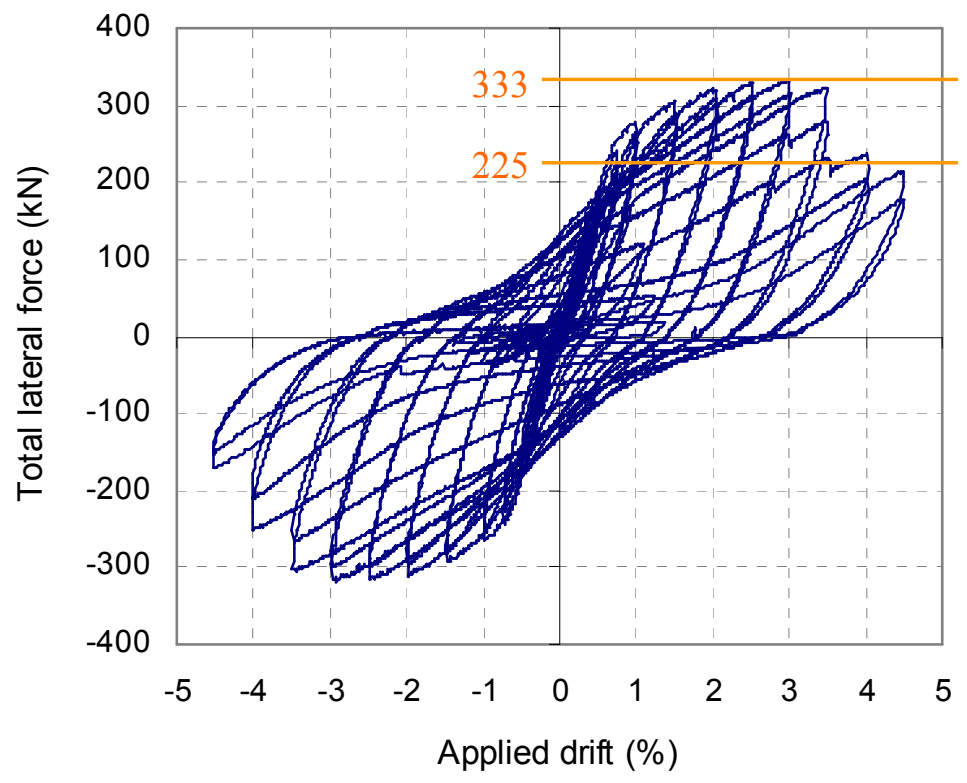

FIGURE 5 - TOTAL FORCE-DISPLACEMENT RELATIONSHIP OF THE SUB-ASSEMBLY

\section{COMputational Modeling}

An analytical model for the sub-assembly test was set up in RUAUMOKO3D [Carr, 2008], an inelastic time-history analysis program. The model contains the newly developed element which predicts elongation in plastic hinges. This element consists of a layer of longitudinal and diagonal springs connected between rigid links at two ends as illustrated in Figure 6(a). The 
longitudinal concrete and steel springs are used to represent the flexural and axial load behavior and the diagonal concrete springs represent the diagonal compression struts in the web that resist shear force. The plastic hinge element is controlled by two key parameters: length of plastic hinge element, $L_{P}$, and length of steel springs, $L_{\text {steel }}$. The length of plastic hinge element is chosen to represent the correct inclination of the diagonal struts as illustrated in Figure 6(b) and specified by (1) where $d-d$ ' is the distance between the centroids of top and bottom reinforcement, $V_{y c}$ is the shear force corresponds to the flexural strength of the beam $M_{y c}, V_{c}$ is the shear resistance of concrete, $A_{v}$ and $f_{v y}$ are the area and yield stress of stirrups. The length of steel springs is taken as the length over which the reinforcement yields and can be expressed by (2) where $M / V$ is the moment to shear ratio, $M_{\max }$ is the maximum moment sustained in the beam, $L_{t}$ is the length of tension shift effect and $L_{e}$ is the length of yield penetration into the support. Details regarding to the development and verification of the plastic hinge element are described elsewhere [Peng et al, 2008; Peng et al, 2007].

$$
\begin{aligned}
& L_{P}=\frac{d-d^{\prime}}{\tan \theta}=\frac{V_{y c}-V_{c}}{A_{v} f_{v y}} \\
& L_{\text {steel }}=\frac{M}{V} \frac{M_{\text {max }}-M_{y c}}{M_{\text {max }}}+L_{t}+L_{e}
\end{aligned}
$$

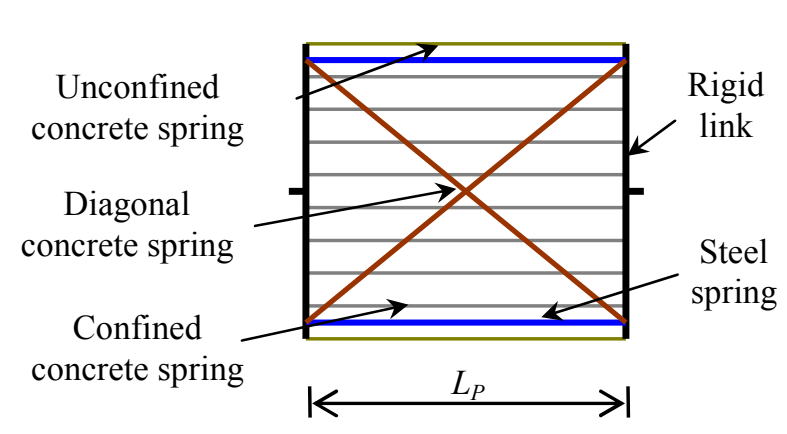

(a) Plastic hinge element

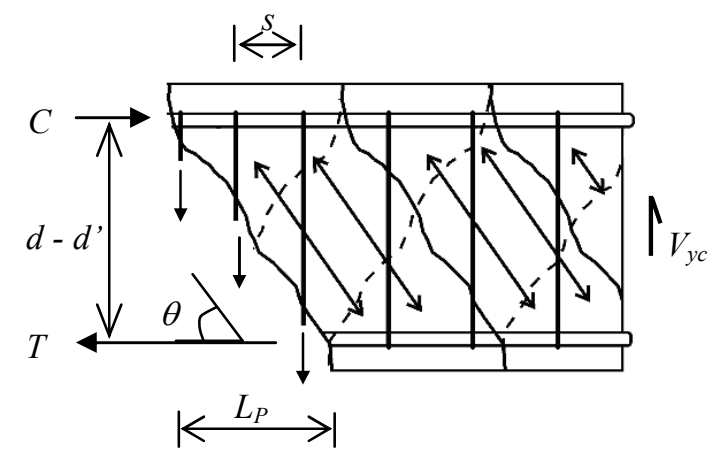

(b) Force equilibrium across a diagonal crack

\section{FIGURE 6 - PLASTIC HINGE ELEMENT}

The overall layout of the analytical model is illustrated in Figure 7. It can be seen that it contains several layers of nodes and elements located at the centre line of each member section. The floor topping is modeled using elastic quadrilateral shell elements, which consider plane stress and plate bending. The columns, beam-column joints, transverse beams, elastic portion of longitudinal beams, prestressed ribs and end slab are modeled using elastic Giberson beam elements. The plastic hinges in the longitudinal beams are modeled using the elongating plastic hinge element. Axial truss members are inserted over the "linking slab" (floor slab between the first rib unit and the longitudinal beam) and along the interface between floor topping and transverse beams where large non-linearity is expected.

The ribs, end slab and longitudinal/transverse beams are connected to the floor via rigid links. The column base in the moment resisting frame is restrained against vertical movement only, and the centre beam-column joint is restrained against movement parallel to the frame. The end of interior transverse beam is fixed against vertical movement and the ends of exterior transverse beams are free to move parallel to the frame.

The elastic member properties are based on cracked concrete sections with the effective moment of inertia of the beams being taken as $0.4 I_{\text {gross }}$. The elastic modulus is taken as Young's 
modulus of concrete, $E_{c}$, and the shear modulus of member, is taken as $0.4 E_{c}$. These values are consistent with the New Zealand Standard, NZS3 101:2006 [Standards New Zealand, 2006]. The torsional second moment of area, $J$, was taken as $b h\left(b^{2}+h^{2}\right) / 12$, where $b$ and $h$ are the width and depth of the section. Nominal torsional capacity of the transverse beam, $T_{n}$, is based on torsional capacity of reinforcement specified in NZS3101:2006 and is given in (3) where $A_{o}$ is the gross area enclosed by shear flow path, $A_{t}$ is the area of one leg of closed stirrup, $s$ is the spacing of stirrup, $A_{l}$ is the area of longitudinal bars, and $p_{o}$ is the length of perimeter of section measured between centers of the corner reinforcing bars.

$$
T_{n}=2 A_{o} \sqrt{\frac{A_{t} f_{v y}}{s} \frac{A_{l} f_{y}}{p_{o}}}
$$

The linking slab is modeled using strut and tie analogy. The diagonal struts are modeled using concrete springs and the transverse ties are modeled using steel springs. The length of the concrete spring is taken as the length of the element. The length of the steel spring is taken as the clear width of the linking slab plus half of the development length, $l_{d b}$, based on NZS3101:2006, plus yield penetration length into the longitudinal beam.

It is assumed that the moment capacity of the interface between floor topping and transverse beams is negligible due to wide cracks developed as a result of plastic hinge elongation. Therefore, the interface is simulated by a series of axial steel and concrete springs along the transverse beams. The length of the steel spring is taken as half of the development length, $l_{d b}$, plus yield penetration length into the transverse beam.

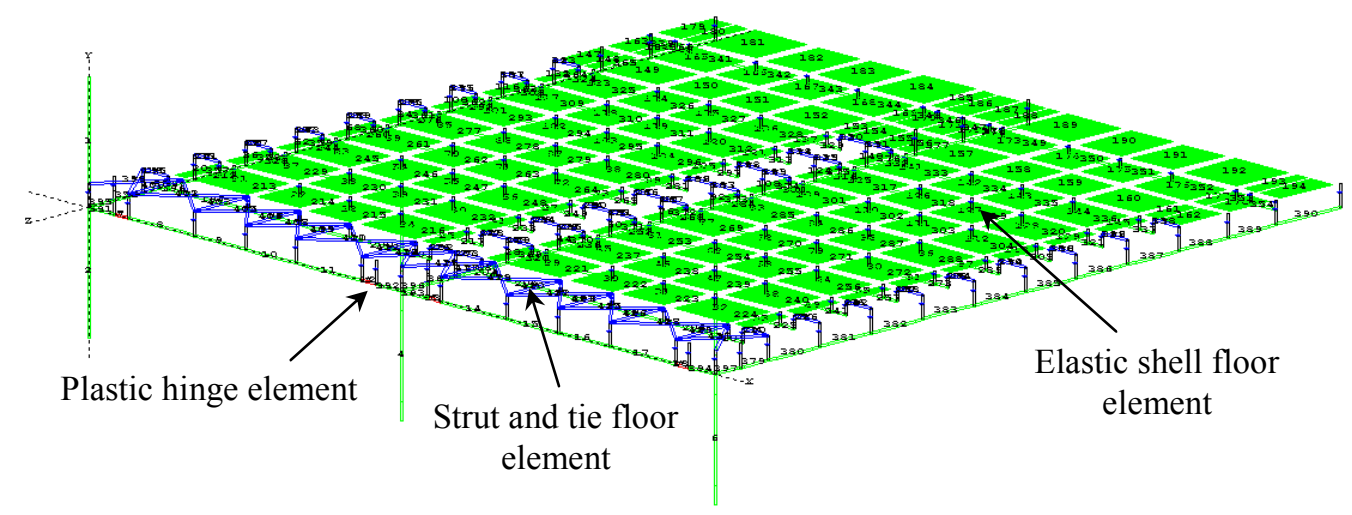

FIGURE 7 - LAYOUT OF THE 3D ANALYTICAL MODEL

In the test, the column displacements were applied iteratively to allow elongation of beam plastic hinges to develop freely. The same displacement history could not be directly feed into the analysis because it would artificially generate the same elongation as in the test. To resolve this problem, it was assumed that the flexural and shear deformation of column was negligible and hence rotation was imposed to the centre of each beam-column joint.

\section{ANALYTICAL AND EXPERIMENTAL COMPARISONS}

The analytical and experimental force-displacement relationships up to $3 \%$ drift are shown in Figure 8. It can be seen that the analysis predicts both the loading and unloading stiffness together with the yield force and forces sustained at peak displacements accurately. This model has not been calibrated to fit the experimental results. The main difference between this model and other models is that it contains elongating plastic hinge elements as well as shell and truss 
like floor elements that allow floor to interact with frames. These elements are based on stress strain relationships of concrete and reinforcement and they do not required calibration.

Pinching was underestimated in the analysis due to two main actions. Firstly, the plastic hinge element underestimates shear deformation in plastic hinges by up-to $50 \%$ before strength degradation occurs. This has been reported in the previous papers [Peng et al, 2008; Peng et al, 2007] and more research is being carried out to improve this deficiency. Secondly, beam bars were observed to slip within the central beam-column joint which is not considered in the analysis.

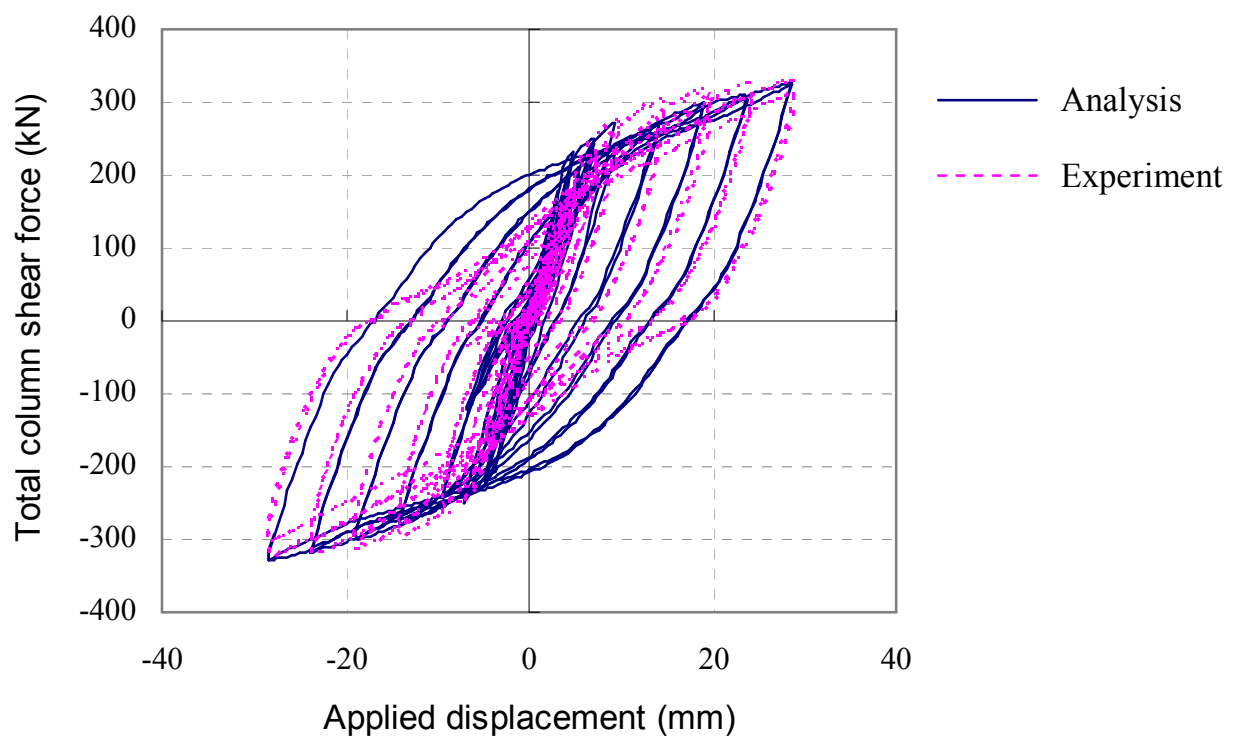

FIGURE 8 - ANALYTICAL AND EXPERIMENTAL FORCE-DISPLACEMENT COMPARISONS

Enhancement in the column shear force, observed in the experiment and analysis, arises due to two main mechanisms: Firstly, reinforcement in the slab participates to the negative flexural strength of the beam (i.e., when tension is on the top). From the observed crack widths measured at the weak section along the transverse beam - floor slab interface, the number of bars which yielded in the slab can be interpreted and the corresponding tension force can be determined. The estimated tension force in the exterior and interior plastic hinges was $95 \mathrm{kN}$ and $240 \mathrm{kN}$ respectively. The tension force predicted in the analysis was $90 \mathrm{kN}$ and $300 \mathrm{kN}$.

Secondly, torsional resistance of the transverse beams increased column shears in both directions. It is difficult to separate out the torsional resistance of transverse beams from the experimental results. At the end of the test the longitudinal beams were removed and displacements were re-applied to the columns to measure the torsional resistance of the transverse beams. The total column shear force obtained from the torsional test at $3 \%$ drift was $30 \mathrm{kN}$. However, the transverse beams had been extensively cracked prior to this torsional test and the actual torsional resistance of transverse beams could have been much higher than the meaured value. The torsional resistance found in the analysis was $60 \mathrm{kN}$. Note that tension force in the floor slab also increases the torsional strength of the transverse beams in one direction.

The analytical and experimental elongation histories are plotted in Figure 9. It can be seen that the analysis predicts elongation of the interior plastic hinge accurately. The analysis predicts elongation of exterior plastic hinge accurately up to $2.5 \%$ drift. Analytical elongation is smaller in the negative drifts than the positive drifts because reinforcement in the floor slab induced axial 
compression force to the plastic hinges in the negative drift cycles. It is uncertain at this stage why elongations at positive and negative drifts are the same in the experiment.

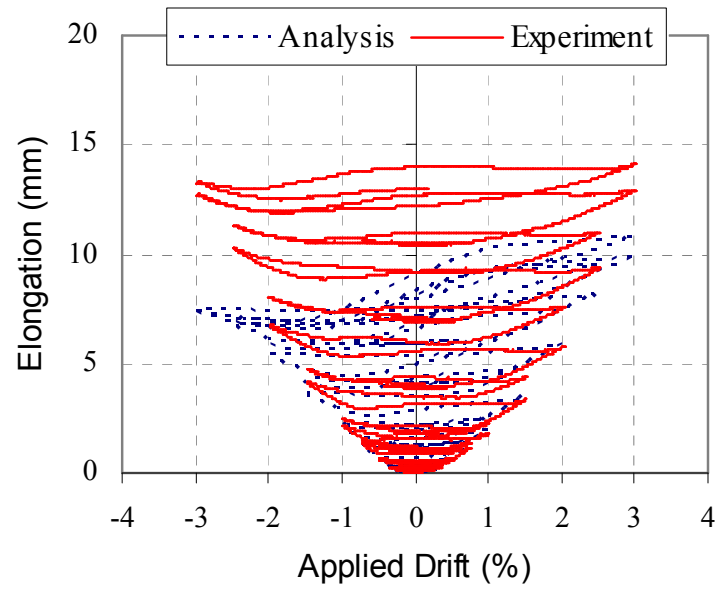

(a) West bay exterior plastic hinge

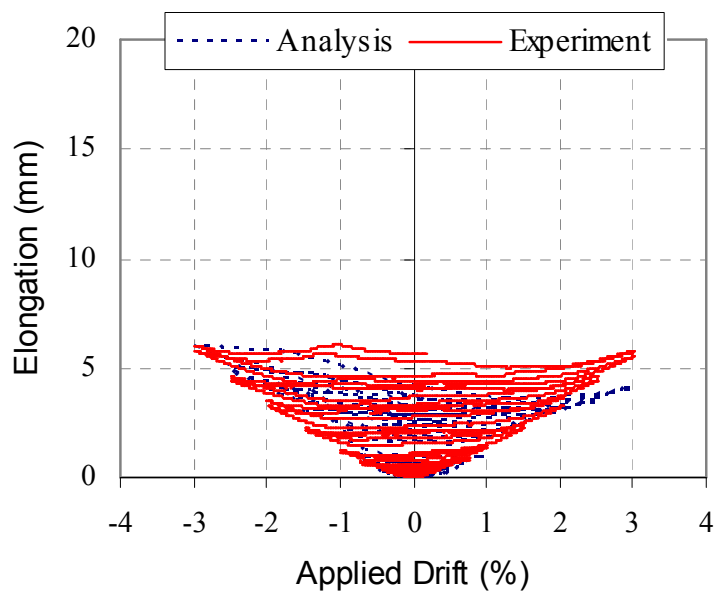

(b) West bay interior plastic hinge

FIGURE 9 - ANALYTICAL AND EXPERIMENTAL ELONGATION COMPARISONS

\section{CONCLUSIONS}

The results in this paper highlight the importance of floor participation in the post yield behavior of beams in reinforced concrete moment resisting frames. The experimental and analytical results show that the current ACI building code underestimates the flexural strength of beams where prestressed flooring units are used in adjacent floors. The analytical model set up in this paper can be used to predict the interaction of beams and floor slabs under inelastic cyclic actions.

\section{REFERENCES}

[1] Lau, D.B.N., "Influence of precast prestressed flooring on the seismic performance of reinforced concrete perimeter frame buildings", $P h D$ thesis, Department of Civil and Environmental Engineering, University of Auckland, New Zealand, 2007. pp. 368.

[2] Matthews, J., "Hollow-core floor slab performance following a severe earthquake", PhD thesis, Department of Civil Engineering, University of Canterbury, New Zealand, 2004, pp. 521.

[3] American Concrete Institute, "Building code requirements for structural concrete and commentary (ACI 318M05)", Farmington Hills, MI: American Concrete Institute, 2005, pp.436.

[4] Jirsa, J.O., "Design of beam-column joints for seismic resistance", Detroit, Mich.: American Concrete Institute, 1991, xi, 518.

[5] Carr, A.J., "RUAUMOKO3D - Inelastic Dynamic Analysis", Department of Civil Engineering, University of Canterbury, New Zealand, 2008.

[6] Peng, B.H.H., Dhakal, R., Fenwick, R., Carr, A., and Bull, D., "Analytical model of ductile reinforced concrete frames allowing for elongation of plastic hinges", Eleventh East Asia-Pacific Conference on Structural Engineering \& Construction, 2008. Taipei, Taiwan.

[7] Peng, B.H.H., Dhakal, R., Fenwick, R., Carr, A., and Bull, D., "Flexural, shear and elongation response of plastic hinges in reinforced concrete member", 8th Pacific Conference on Earthquake Engineering, 2007. Singapore.

[8] Standards New Zealand, “Concrete Structures Standard: NZS 3101:2006”, Standards New Zealand, Wellington, 2006. 